\title{
PEMANFAATAN SCIENCE IN BOX DALAM PEMBELAJARAN BERBASIS INKUIRI DI SMP UNTUK MENINGKATKAN PENGUASAAN KONSEP FLUIDA STATIS
}

\author{
Abdurrahman \\ Program Studi Magister Keguruan IPA FKIP Universitas Lampung, Bandar Lampung \\ Email: Abdurrahman.1968@fkip.unila.ac.id
}

Diterima: 11 September 2016. Disetujui: 12 Oktober 2016. Dipublikasikan: Oktober 2016

\begin{abstract}
The purpose of this study is to describe the effectiveness of engagement in science across science teaching and learning activities using for Statics Fluid concept in the context of scientific inquiry. Action reseach method was used to solve problem of lack of practical work in science students. The analysis employs a quantitative approach that includes descriptive and inferential statistics to examine characteristics and effectiveness SBFS developed. The research result showed that there was significant main effects of inquiry instruction and teaching context using Science in Box on student conceptual change. The result suggested that Teaching strategies that actively engage students in the learning process through scientific investigations using practical work are more likely to increase conceptual understanding than are strategies that rely on more conventional techniques.
\end{abstract}

\begin{abstract}
Abstrak: Tujuan dari penelitian ini ialah untuk menjelaskan efektifitas keterikatan ilmu sains dengan kegiatan pengajaran dan pembelajaran sains menggunakan konsep Fluida Statis berbasis inkuiri. Metode action research digunakan untuk memecahkan masalah kurangnya pelaksanaan praktik pada siswa sains. Analisis data menggunakan pendekatan kuantitatif yang meliputi statistik deskriptif dan inferensial untuk menguji karakteristik dan efektifitas SBFS yang dikembangkan. Hasil penelitian menunjukkan bahwa ada pengaruh yang signifikan dari pembelajran dan kpengajaran inkuiri menggunakan Science in Box terhadap penguasaan konsep fluida statis siswa. Hasilnya menunjukkan bahwa strategi Pengajaran yang secara aktif melibatkan siswa dalam proses pembelajaran melalui penyelidikan ilmiah menggunakan kerja praktek lebih mungkin untuk meningkatkan penguasaan konseptual siswa dibandingkan strategi yang mengandalkan teknik yang lebih konvensional.
\end{abstract}

(C) 2016 Pendidikan Fisika, FTK IAIN Raden Intan Lampung

Kata kunci: Science in Box, Statics Fluid, Inquiry learning.

\section{PENDAHULUAN}

Hampir di seluruh belahan dunia, akhir-akhir ini telah cukup banyak dilakukan reformasi pembelajaran sains yang merubah orientasi pembelajaran sains hanya sebagai body of knowledge (konten sains) kepada peningkatan penguasaan proses atau prosedur sains yang melibatkan siswa mengamati dan memanipulasi objek dan bahan kajian sains secara nyata di sekolah (Abrahams dan Millar, 2008). Selain itu, sebagai upaya memperoleh perubahan konsep dan meningkatkan capaian pembelajaran sains secara signifikan, maka lingkungan belajar sains di sekolah harus menghadirkan percobaan atau eksperimen secara langsung (hands-on), pengalaman belajar yang kontekstual dan investigasi berbasis penyelidikan atau inkuiri (NSTA, 2007; NRC, 2006). Aktivitas ilmiah semacam itu harus dilakukan di dalam laboratorium, di dalam kelas, atau di lapangan (outdoor activity) dimana siswa diberikan kesempatan untuk berinteraksi secara langsung dengan fenomena alam 
yang muncul atau dengan sejumlah data atau fakta akurat mengenai fenomena tersebut (NSTA, 2007).

Telah banyak dilakukan penelitian yang difokuskan pada keterlibatan secara langsung siswa dalam investigasi ilmiah melalui praktek yang melibatkan aktivitas mental dan fisik di laboratorium, kelas, atau ruang fisis lainnya, atau beinteraksi langsung dengan peralatan praktikum yang sekaligus menunjukkan adanya pengaruh positif terhadap capaian pembelajaran siswa (Zacharia et al., 2008; Akpan dan Strayer 2010; Ozgelen, 2012; Toplis, 2011). Hasil ini menunjukkan bahwa praktek sains atau hands-on experiment masih merupakan strategi pembelajaran yang efektif dalam kelaskelas sains.

Dalam konteks pembelajaran berbasis inkuiri (inquiry-based learning), fase-fase kegiatan penyelidikan ilmiah menggunakan sejumlah tools laboratorium akan meningkatkan proses aktivitas saintifik siswa (NRC, 2006; NSTA, 2007; Akpan dan Strayer 2010;). Pengaturan fase pada kegiatan eksperimen tersebut juga dapat meningkatkan keterlibatan dan motivasi melalui manipulasi kinestetik dari bahan-bahan dan peralatan fisik. Pengaturan sintaks pembelajaran tersebut juga dapat memudahkan konseptualisasi (pembentukan konsep) dari suatu hal yang konkret menuju suatu hal yang abstrak (Ozgelen, 2012), dan dapat membantu siswa menghubungkan penemuan sains dengan dunia nyata (NRC, 2006; NSTA 2007), sehingga pembelajaran sains terasa lebih bermakna dan tidak membosankan.

Millar et al (2009) telah mengembangkan model analitik peran kerja praktek sebagai sebuah strategi pembelajaran dengan level/tingkat efektivitas paling menonjol, dibandingkan dengan ketika siswa hanya mempelajari sains melalui penalaran saja (lihat gambar 1). Berdasarkan gambar 1, nampak bahwa merumuskan tujuan pembelajaran secara jelas dan tearah merupakan langkah awal yang sangat berperan dalam merumuskan keterlibatan dan kinerja siswa dalam belajar sains. Setiap materi/konsep yang berbeda membutuhkan perumusan tujuan yang spesifik, agar tugas yang harus dilakukan oleh siswa juga dirumuskan dengan lebih jelas serta aktivitas mental dan fisik yang harus diperankan siswa dilakukan dengan baik, bukan sekedar merumuskan apa yang harus dipelajari siswa di kelas. Dengan demikian pendekatan saintifik dengan teknik praktikum sains diharapkan memiliki peran menonjol dalam menciptakan pembelajaran sains secara efektif. 


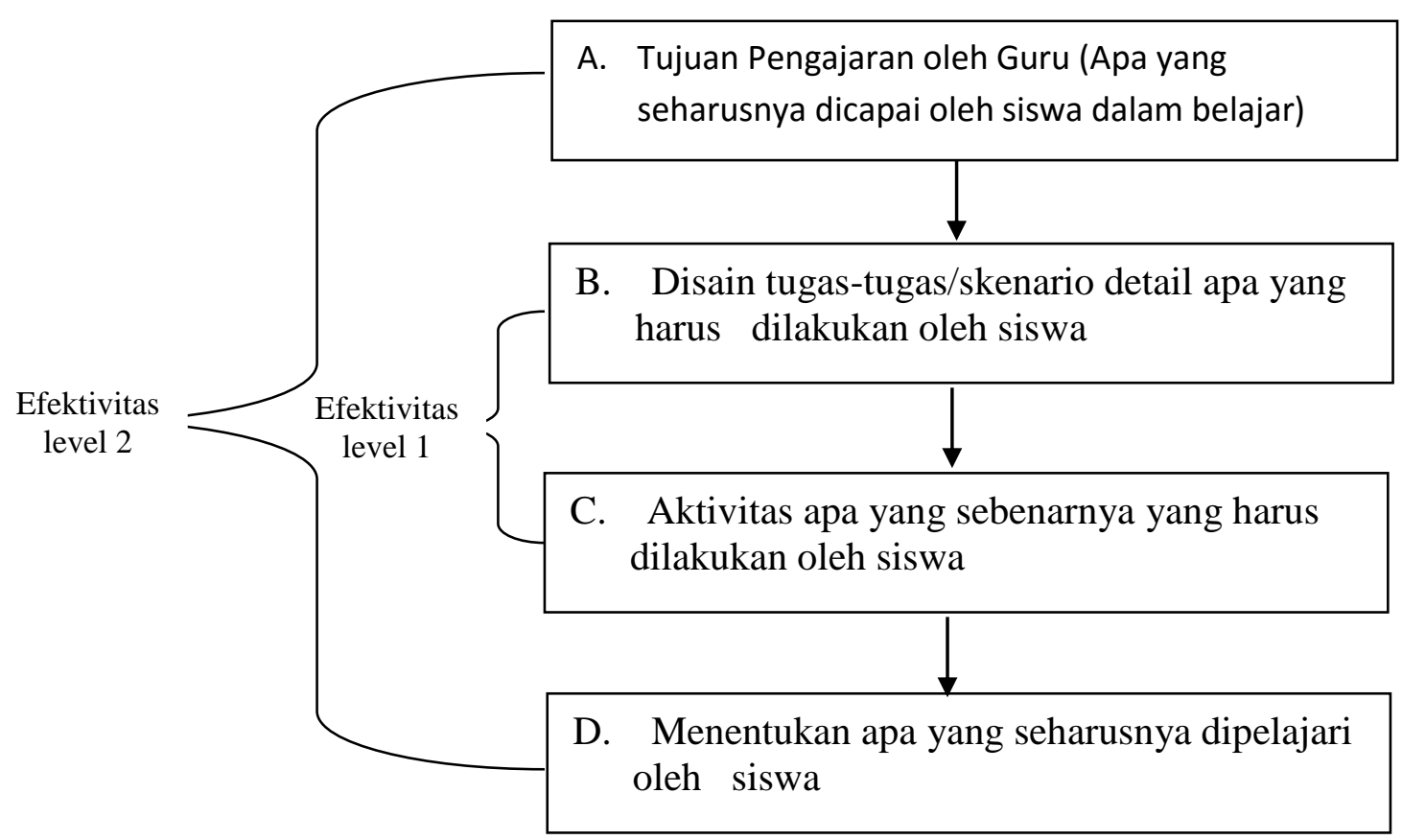

Gambar 1. Levelisasi Efektivitas Pembelajaran Sains yang melibatkan praktek ilmiah (Millar et al, 1999)

Walaupun metode eksperimen (hands-on) sangat vital perannya dalam pembentukan efektivitas belajar sains siswa, namun kenyataannya di lapangan kita sering menemukan bahwa pendekatan eksperimen saintifik yang berpusat pada peralatan fisik, bahan-bahan fisik, dan fasilitas fisik kadang sulit dilakukan dan penuh keterbatasan (Stone, 2007; Klahr at al., 2007), mungkin saja juga membutuhkan biaya yang mahal (Huppert et al. 2002), dan akibatnya dapat membatasi daya akses siswa, terutama di sekolah-sekolah yang memiliki peralatan terbatas (Stone, 2007). Khususnya di beberapa daerah di Indonesia, masih terdapat sekolah satu atap (SATAP) dalam penyelenggaraan pendidikan dasar, yang umumnya berada pada wilayah dengan daya jangkau yang cukup jauh dan tidak memiliki ruang laboratorium yang memadai. Penelitian ini mencoba untuk mengatasi kelemahan pembelajaran sains di salah satu SMP di Provinsi Lampung melalui pengembangan dan penerapan Science in Box untuk materi Tekanan Hidroststis yang bahannya diperoleh dari lingkungan sekitar siswa. Implementasi pembelajaran inkuiri menggunakan peralatan hand made tersebut diajukan untuk menjawab pertanyaan penelitian sebagai berikut: Apakah pembelajaran berbasis inkuiri menggunakan perangkat Science in Box dapat meningkatkan penguasan konsep fluida statik siswa SMP.

\section{METODE PENELITIAN}

Studi ini menggunakan metode penelitian tindakan (action research). Menurut Cohen \& Manion (1989) metode action research merupakan studi yang dilakukan oleh peneliti untuk menyelesaikan masalah. Berangkat dari masalah kekurangan alat peraga IPA pada topik Fluida statis, maka telah dikembangkan Science in-Box Fluida Statis (SBFS) yang dibuat dari bahanbahan bekas yang ada pada lingkungan siswa seperti botol plastik bekas air mineral, selang plastik, papan kayu, dan lain-lain. Agar SBFS ini layak diimplementasikan, telah dilakukan 
validasi ahli dan revisi serta ujicoba lapangan skala kecil dan revisi produk.

Partisipan dalam penelitian ini meliputi: 1 orang dosen ahli materi (Fisika); 1 orang dosen ahli media pembelajaran; 4 orang Guru senior bersertifikasi sebagai instructional expert judgment, dan 27 orang siswa salah satu SMP Satu Atap (SATAP) di Provinsi Lampung. Secara lengkap demografi partisipan penelitian ini adalah sebagai berikut:

Tabel 1. Demografi Partisipan untuk validasi SBFS

\begin{tabular}{llll}
\hline Subjek & Jumlah & Status & Jenis Kelamin \\
\hline Ahli Materi & 1 & Pakar & Laki-Laki \\
Ahli Media & 1 & Pakar & Laki-Laki \\
Ahli Pembelajaran & 2 & Guru Senior & 1 laki-laki; \\
& & & 1 perempuan \\
\hline
\end{tabular}

Validasi ahli dan uji lapangan skala kecil dilakukan dengan menggunakan kuisioner dengan sejumlah pertanyaan meliputi aspek ketepatan, kesesuaian, kemanfaatan, dan kemenarikan dengan skor berdasarkan 5 poin skala Likert mulai dari 1 (sangat tidak setuju) sampai 5 (sangat setuju). Sedangkan uji lapangan skala lebih luas (pilot sudy) dilakukan melalui desain eksperimen one shot case study untuk menguji efektivitas penggunaan SBFS yang dikembangkan dalam konteks pembelajaran berbasis inkuri ilmiah dengan disain kuasi eksperimen (lihat Gambar.1).

\begin{tabular}{|llll|}
\hline Kelompok & $\mathrm{O}_{1}$ & $\mathrm{X}$ & $\mathrm{O}_{2}$ \\
\hline
\end{tabular}

Gambar 2. Disain kuasi-eksperimen one group pre-posttest untuk uji skala lebih luas (Fraenkel \& Wallen, 2008).

Analisis deskriptif analitik dilakukan untuk menggambarkan hasil uji ahli dan uji skala kecil, sedangkan uji-t paired sample dilakukan unutk menguji lapangan skala lebih luas. Adapun langkah-langkah inkuiri ilmiah yang dilakukan dalam pembelajaran menggunakan SBTH diadaptasi dari fase pembelajaran inkuri menurut Pedaste et al (2015) yang meliputi: Orientation (orientasi), Conceptualization (konseptualisasi), Investigation (investigasi), Discussion (Diskusi yang meliputi kegiatan komunikasi dan refleksi), dan Conclusion (Penyimpulan).

\section{HASIL DAN PEMBAHASAN}

Science in Box-Fluida Statik (SBFS) hasil pengembangan dapat dilihat pada gambar 2 di bawah ini. Hampir semua komponen terbuat dari bahan-bahan bekas yang mudah diperoleh di sekitar siswa. Dalam penelitian ini telah dilakukan beberapa percobaan menggunakan SBFS dalam konteks pembelajaran inkuiri Pedaste et al (2015), diantaranya: (1) Tekanan Hidrostatik, (2) Hukum Pascal, (3) Efek Hartl, dan (4) Bejana Berhungan, dan (5) Terapung, Melayang, dan Tenggelam. 

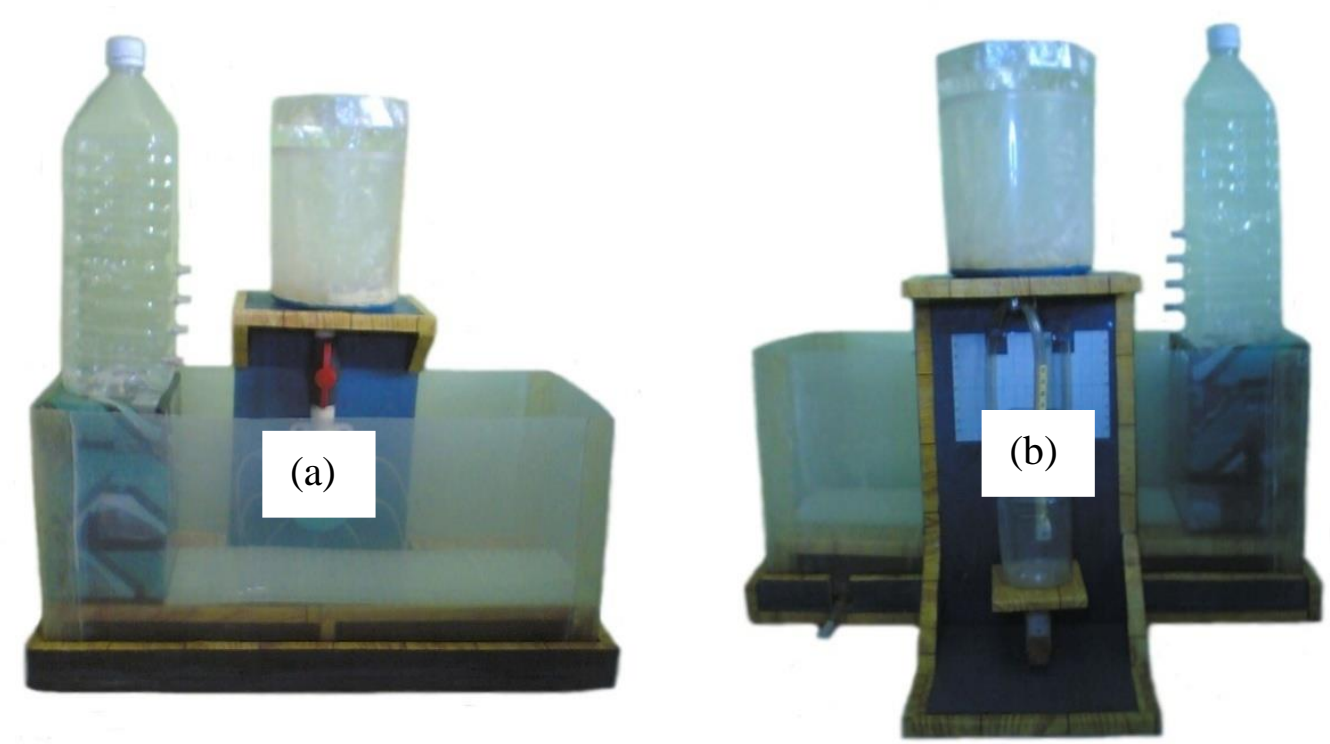

Gambar 3. Science in Box Fluida Statik (SBFS) hasil Pengembangan

(a) Tampak depan; (b) Tampak Belakang

Berdasarkan hasil validasi ahli, SBFS hasil pengembangan memenuhi syarat didaktik sebagai Kit IPA sederhana yang dapat digunakan dalam membangun kemampuan inkuiri siswa. Hasil validasi ahli selengkapnya dapat dilihat pada
Tabel 2. Selain itu para validator juga menilai bahwa SBFS menarik dan sangat bermanfaat bagi perubahan konseptual siswa ke arah yang lebih baik

Tabel 2. Hasil Validasi Ahli SBFS

\begin{tabular}{|c|c|c|c|}
\hline \multirow[b]{2}{*}{ Validator } & \multicolumn{3}{|c|}{ Aspek yang dinilai } \\
\hline & $\begin{array}{l}\text { Kesesuain } \\
\text { (kategori) }\end{array}$ & $\begin{array}{l}\text { Kemenarikan } \\
\text { (kategori) }\end{array}$ & $\begin{array}{l}\text { Kemanfaatan } \\
\text { (kategori) }\end{array}$ \\
\hline Pakar 1 & $\begin{array}{l}4,60 \\
\text { (Sangat baik) }\end{array}$ & $\begin{array}{l}3,51 \\
\text { (menarik) }\end{array}$ & $\begin{array}{l}4,08 \\
\text { (Sangat bermanfaat) }\end{array}$ \\
\hline Pakar 2 & $\begin{array}{l}4,33 \\
\text { (Sangat baik) }\end{array}$ & $\begin{array}{l}3,56 \\
\text { (menarik) }\end{array}$ & $\begin{array}{l}4,51 \\
\text { (Sangat bermanfaat) }\end{array}$ \\
\hline Guru 1 & & $\begin{array}{l}3,36 \\
\text { (menarik) }\end{array}$ & $\begin{array}{l}3,5 \\
\text { (Bermanfaat) }\end{array}$ \\
\hline Guru 2 & & $\begin{array}{l}4,05 \\
\text { (Sangat Menarik) }\end{array}$ & $\begin{array}{l}4,58 \\
\text { (Sangat bermanfaat) }\end{array}$ \\
\hline
\end{tabular}

Kemudian berdasarkan hasil uji efektivitas pembelajaran inkuiri dengan menerapkan SBFS menunjukkan bahwa terjadi peningkatan penguasaan konsep IPA pada topik Fluida Statis secara signifikans $(p<0,05)$ seperti terlihat pada hasil uji paired-sample t-test antara pre dan post-test pada Tabel 3. di bawah ini. Dengan demikian maka penerapan SBFS dalam strategi inkuiri dapat meningkatkan hasil belajar Sains siswa pada topik Fluida Statis. 
Tabel 3. Data desksriptif dan hasil uji paired-sample t-test

\begin{tabular}{lllll}
\hline & N & M & SD & $t$ \\
\hline Pre-test & 27 & 52,93 & 7,96 & $-29,09^{\text {a }}$ \\
Post test & 27 & 81,41 & 6,47 & \\
\hline
\end{tabular}

${ }^{\mathrm{a}} p<0,05$

Salah satu hasil penting dari penerapan SBFS adalah munculnya minat belajar saian $\mathrm{s}$ secara kolaboratif dikalangan siswa. Dengan kata lain mereka telah membangun komunitas pembelajaran sains yang lingkungan belajarnya bersifat kontemporer melalui percobaan secara langsung menggunakan alat peraga yang diperoleh dari lingkungan sekitar. Hal ini berdampak pada terbentuknya pengalaman belajar dan investigasi berbasis inkuiri, sehingga dapat meningkatkan perubahan konsep siswa atau conceptual change (NSTA, 2007; NRC, 2006). Melalui investigasi semacam itu yang dilakukan di dalam laboratorium, kelas, atau di lapangan jika mungkin, dimana siswa diberikan kesempatan untuk berinteraksi secara langsung dengan fenomena alam yang muncul atau dengan data hasil pengamatan yang akurat mengenai fenomena tersebut, maka secara tidak langsung membentuk pemahaman konsep mendalam bagi siswa (NSTA, 2007).

Interaksi siswa dengan alat-alat praktikum sederhana dalam konteks pembelajaran inkuiri ini, ternyata membantu keterampilan aktivitas fisik siswa berupa eksperimen sains yang sesungguhnya (Klahr et al. 2007; Zacharia et al. 2008; Kirschner dan Huisman 1998). Aktivitas fisik secara kolaboratif akan mampu memicu siswa dalam kreativitas kognitif yang pada akhirnya akan berdampak pada pembentukan pembaharuan konsep yang sangat signifikan pada diri siswa (Akpan dan Strayer 2010). Chiappetta dan Adams (2004) mengungkapkan bahwa pembelajaran inkuiri merupakan langkah nyata dalam menyatukan kekuatan pemahaman science content knowledge (pengetahuan konten sains) dan keterampilan proses sains secara sinergis dan efektif. Dengan demikian dalam konteks pendekatan pegagogis, inkuiri dengan memanfaatkan science in box buatan sendiri dengan memanfaatkan bahan-bahan sekitar kita, akan mampu menghadirkan pembelajaran berpusat pada siswa yang bercirikan aktivitas dalam pencapaian dimensi kognitif baik produk maupun proses yang melibatkan siswa pada berbagai aktivitas inkuiri sehingga capaian pembelajaran (learning outcome) yang diharapkan akan meningkat secara signifikans (Bunterm et al, 2014).

\section{SIMPULAN}

Penelitian ini telah berhasil mengeliminasi permasalahan kurangnya alat-alat laboratorium IPA pada topiktopik esensial seperi Fluida Statis melalui pengembangan Science in Box Fluida Statis (SBFS). SBFS telah mampu meningkatkan aktivitas inkuri siswa SMP sehingga berdampak pada peningkatan penguasaan konsep siswa secara signifikans. Aktivitas inkuiri dengan memanfaatkan barang-barang bekas untuk melakukan sejumlah percobaan konsep dan hukum fluida statis, ternyata efektif dalam membangun kolaborasi dan interaksi sosial yang berdampak pada peningkatan perubahan konseptual siswa.

\section{UCAPAN TERIMAKASIH}

Penelitian ini merupakan penelitian institusi yang dibiayai oleh DIPA BLU FKIP Universitas Lampung tahun 2015. Terimakasih pada semua pihak yang turut berperan dan bekerjasama dalam penelitian ini, dan semoga hasil penelitian 
ini bermanfaat dalam pengembangan pendidikan sains di Indonesia.

\section{DAFTAR PUSTAKA}

Abrahams, I. \& Milar, R. (2012). Does Practical Work Really Work? A study of the effectiveness of practical work as a teaching and learning method in school science. International Journal of Science Education, 30(14), pp. 19451969.

Akpan J, Strayer J. (2010). Which comes first the use of computer simulation of frog dissection or conventional dissection as academic exercise? J Comput Math Sci Teach 29(2):113-138

Bybee, R. W. (2006). Enhancing science teaching and student learning: A BSCS perspective. Paper presented at the ACER Research Conference. Canberra, ACT, Australia

Bunterm, T., Lee, K., Ng Lan Kong, J., Srikoon, S., Vangpoomnyai, P., Rattanavongsa, J., dan Rachahoon, G. (2014). Do Difeerent Levels of Inquiry Lead to Different Learning Outcomes? A Comparison between guided and structured inquiry. International Journal of Science Education, 36(12), 19371959.

Chiappetta, E.L., dan Adams, A.D. (2004). Inquiry-based instruction: Understanding how content and process go hand-in-hand with school science. The science Teacher, 71(2), 46-50.

Cohen, L. \& Manion, L. (1989). Research Methods in Education. Routeledge and Kegan Paul: London.

Fraenkel, J. R., and N. E. Wallen. (2008). Introduction to qualitative research: How to Design and Evaluate Research in Education, 7th ed. Boston, MA: McGraw-Hill International Edition.
Huppert J, Lomask SM, Lazarowitz R. (2002) Computer simulations in the high school: students' cognitive stages, science process skills and academic achievement in microbiology. Int $\boldsymbol{J}$ Sci Educ, 24(8):803-821

Kirschner P, Huisman W (1998) 'Dry laboratories' in science education; computer-based practical work. Int J Sci Educ, 20(6): 665

Klahr D, Triona LM, Williams C. (2007) Hands on what? The relative effectiveness of physical versus virtual materials in an engineering design project by middle school children. J Res Sci Teach, 44(1):183-203. doi:10.1002/tea.20152

Millar, R., Le Maréchal, J.-F., \& Tiberghien, A. (1999). 'Mapping' the domain: Varieties of practical work. In J. Leach \& A. Paulsen (Eds.), Practical work in science education-Recent research studies (pp. 33-59). Roskilde/Dordrecht, The Netherlands: Roskilde University Press/Kluwe

NRC (National Research Council). (1996). National science education standards. Washington, DC: National Academies Press.

NSTA (National Science Teacher Association). (2007) NSTA position statement: the use of computers in science education.

Ozgelen, S. (2012). Students Science process skills within a cognitive domain framework. Eurasia Journal of Mathematics, Science \& Technology Education, 8(4), 283-292.

Pedaste, M., Mäeots, M., Siiman, L.A., de Jong, T., van Riesen, S.A.N., Kamp, E.T., Manoli, C.C., Zacharia, Z.C., Tsourlidaki, E. (2015). Phases of inquiry-based learning: Definitions and the 
inquiry cycle. Educational

Research Review, 14, pp.47-61

Stone DC. (2007) Teaching chromatography using virtual laboratory exercises. J Chem Educ 84(9), 1488-null. doi:10.1021/ed084p1 488

Toplis, R. (2011). Student's views about secondary school science lessons: The role of practical work. Research in Science Education. DOI: 10.1007/s11165-011-9209-6.

Zacharia Z, Olympiou G, Papaevripidou M. (2008). Effects of experimenting with physical and virtual manipulatives on students' conceptual understanding in heat and temperature. J Res Sci Teach 45(9):1021-1035.

doi:10.1002/tea.20260. 